\title{
Ferroresonance Phenomenon in Power Transformers - Experimental Assessment
}

\author{
A.S. ABDAllah AND M.A. El-KadY \\ King Saud University, Riyadh, Saudi Arabia \\ ahsaabd@yahoo.co.uk
}

\begin{abstract}
This paper reports on the results of recent research and development efforts to study and assess various impacts of ferroresonance phenomenon on operating performance of power transformers and to investigate ways to mitigate the effects of such phenomenon. Three-phase core-type transformers are used in the study. The results of the technical investigation and the associated ferroresonance experimental work performed showed that ferroresonance can cause dangerous overvoltages and overcurrents in three-phase coretype transformers. Sensitivity analysis results are also presented to determine the impact of various design and operating parameters on the resulting overvoltages and overcurrents caused by ferroresonance.
\end{abstract}

KEY WORDS: Power system transients, Ferroresonance, Transformers, Sensitivity analysis.

\section{Introduction}

With the increase in power-transmission distances, it is logical to expect that in addition to the already exposed problems, new ones may arise which previously have not required consideration. One of the most serious problems in electrical power systems is the possibility of over-voltages resulting from a ferroresonant condition [1-6]. Ferroresonance is a mysterious phenomenon that seems to occur capriciously, causing much concern among utility operating personnel. It generally occurs during system umbalance, usually during switching, that places capacitance in series with transformer magnetizing 
impedance. This can result in high overvoltages that can cause failures in transformers, cables, and arresters. Any system capacitance can be involved in ferroresonance, but we are generally most concerned about underground cable capacitance.

As utilities moved up to $25-$ and $35-\mathrm{kV}$ class cable systems, they found ferroresonance to be much more common than at lower voltage levels. They found they had to be more careful about how they switched the cable and how they arranged switch points to minimize the amount of cable isolated with lightly loaded transformers during switching. Ferroresonance is a greater problem at the higher voltage levels $[3,4,6]$ because the relative ratios of losses, magnetizing impedance and cable capacitance fall into its more favorable range. This phenomena has been extensively studied by many investigators since was first reported in 1930's. From these studies, we can define the ferroresonance phenomena as it is a special case of jump resonance phenomena. Jump resonance refers to circuits containing a nonlinear inductor and a linear capacitor with or without some other elements present [1]. For certain circuit parameters, if an incremental change in the amplitude or frequency of the input to the circuit causes a sudden jump in signal amplitude somewhere in the circuit, jump resonance is said to have occurred. Thus, the jump can be one of voltage, current, flux linkages, or all three.

This paper reports the results of recent research to study and assess various impacts of ferroresonance phenomenon on operating performance of power transformers. Three-phase core-type transformers are used in the study.

\section{Overview of Ferroresonance}

Ferroresonance is a general term applied to a wide variety of interactions between capacitors and iron-core inductors that result in unusual voltages and/or currents [1-5]. In linear circuits, resonance occurs when the capacitive reactance equals the inductive reactance at the frequency at which the circuit is driven. Iron-core inductors have a non-linear characteristic and have a range of inductance values. Therefore, there may not be a case where the inductive reactance is equal to the capacitive reactance, but yet very high and damaging overvoltages occur. In power system the ferroresonance occurs when a nonlinear inductor is fed from a series capacitor [1-4]. The nonlinear inductor in power system can be due to: a) The magnetic core of a wound type voltage transformer, b) Bank type transformer, c) The complex structure of a 3 limb three-phase power transformer (core type transformer), d) The complex structure of a 5 limb three-phase power transformer (shell-type transformer). 
The circuit capacitance in power system can be due to a number of elements, such as: a) The circuit-to-circuit capacitance, b) Parallel lines capacitance, c) Conductor to earth capacitance, d) Circuit breaker grading capacitance, e) Busbar capacitance, f) Bushing capacitance. The phenomena of ferroresonance is a name given to a situation where the nonlinear magnetic properties of iron in transformer iron core interact with capacitance existing in the electrical network to produce a nonlinear tuned circuit with an unexpected resonant frequency. This phenomenon poses a hazard to an electric power system because it generates overvoltages and overcurrents. Poorly understood, it is generally not accounted for in power system studies. It is rare and cannot be analyzed or predicted by the computational methods based on linear approximation normally used by electrical engineers. This lack of knowledge makes it a probable culprit responsible for the unexplained destruction and malfunctioning of equipment.

There are two main circuit configurations that could lead to ferroresonance, namely a) A fuse operates (either correctly or inadvertently), or a lineman pulls an elbow connector for switching purposes. This leaves one or more transformers isolated on a length of cable with one phase open, and b) A threephase transformer energized by manually switched cables, intentionally or inadvertently, some distance up-line from the transformer. This leaves the transformer isolated on a length of cable with two phases open. This seems to be more of a problem when switching cables and transformers at new construction sites. There are two additional conditions that must be met: a) The length of cable between the transformer and the open conductor location must have sufficient capacitance to cause ferroresonance, and b) The losses in the circuit and the resistive load on the transformer must be low. These conditions may be met at a variety of times. The low resistive load requirement is often met on new construction when there may be no load on the transformer or only a few small loads. When the load on the transformer increases after a period of time, ferroresonance becomes less likely. Some common circumstances leading to ferroresonance include transformer fuse blowing, line or switch fuse blowing, energizing a new transformer by manual cable switching upline from transformers, cable connector or splice opening, manual cable switching to reconfigure a cable circuit during emergency conditions, and open conductor fault in overhead line feeding cable.

There are several modes of ferroresonance with varying physical and electrical displays. Some have very high voltages and currents while others have voltages close to normal. There may or may not be failures or other evidence of ferroresonance in the electrical components. Therefore, it may be difficult to tell if ferroresonance has occured in many cases unless there are 
witnesses or power quality recording instruments. Among notable symptoms of ferroresonance are audible noise and overheating.

\section{Experimental Results}

The ferroresonance phenomenon has been studied using three-phase, coretype transformer. The transformer rating is $3 \mathrm{kVA}, 380 \mathrm{~V} / 220 \mathrm{~V}$, core-type, air- cooling, Y-Y connected.

\subsection{Measurement of Ferroresonance at No-Load}

In the circuit of Figure 1, a series capacitor of $\mathrm{C}=4.0 \mu \mathrm{F}$ has been used with all primary phases are connected to supply. Then, the supply voltage has been increased in steps from zero to $300 \mathrm{~V}$ and then reduced in steps also from $300 \mathrm{~V}$ to zero. In each step in the forward direction as well as in the backward direction, the readings of the supply voltage, $\mathrm{V}_{1}$, the primary induced voltages, $\mathrm{V}_{\mathrm{AB}}, \mathrm{V}_{\mathrm{BC}}, \mathrm{V}_{\mathrm{CA}}$, the secondary induced voltages $\mathrm{V}_{\mathrm{ab}}, \mathrm{V}_{\mathrm{bc}}, \mathrm{V}_{\mathrm{ca}}$ and the primary current, I are recorded and depicted in figures $2-4$. The voltages and current are measured using True RMS meters.

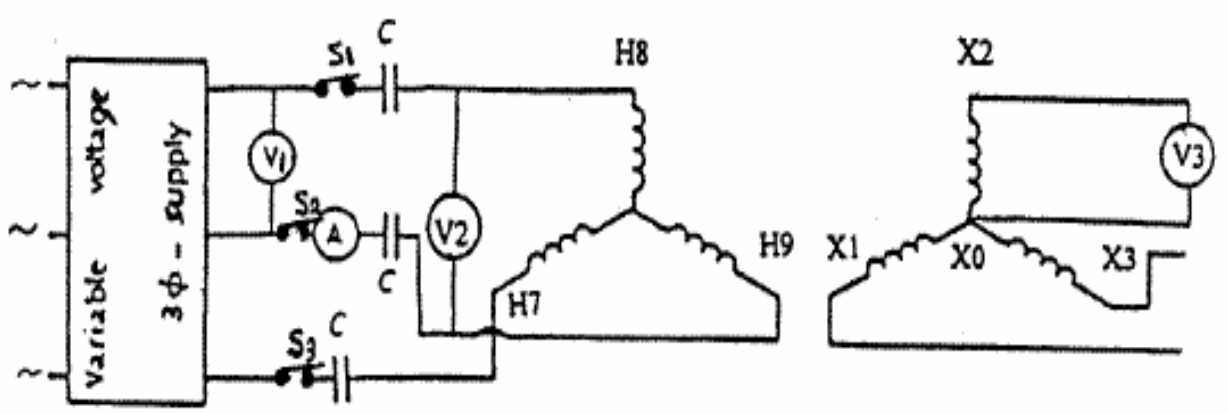

Fig. 1: Ferroresonance circuit diagram with transformer at no-load.

From Figures 2-4, it could be seen that a jump in current due to ferroresonance has occurred at supply voltage $\mathrm{V}_{1}=200$ volts causing:

1. Jump-up in the primary induced voltage that could reach as large as $\Delta \mathrm{V}_{\mathrm{AB}}$ $=240$ volts.

2. Jump-up in the secondary induced voltage that could reach as large as $\Delta \mathrm{V}_{\mathrm{ab}}=140$ volts.

3. Jump-up in the primary current that could reach as large as $\Delta \mathrm{I}=0.56$ amperes. 


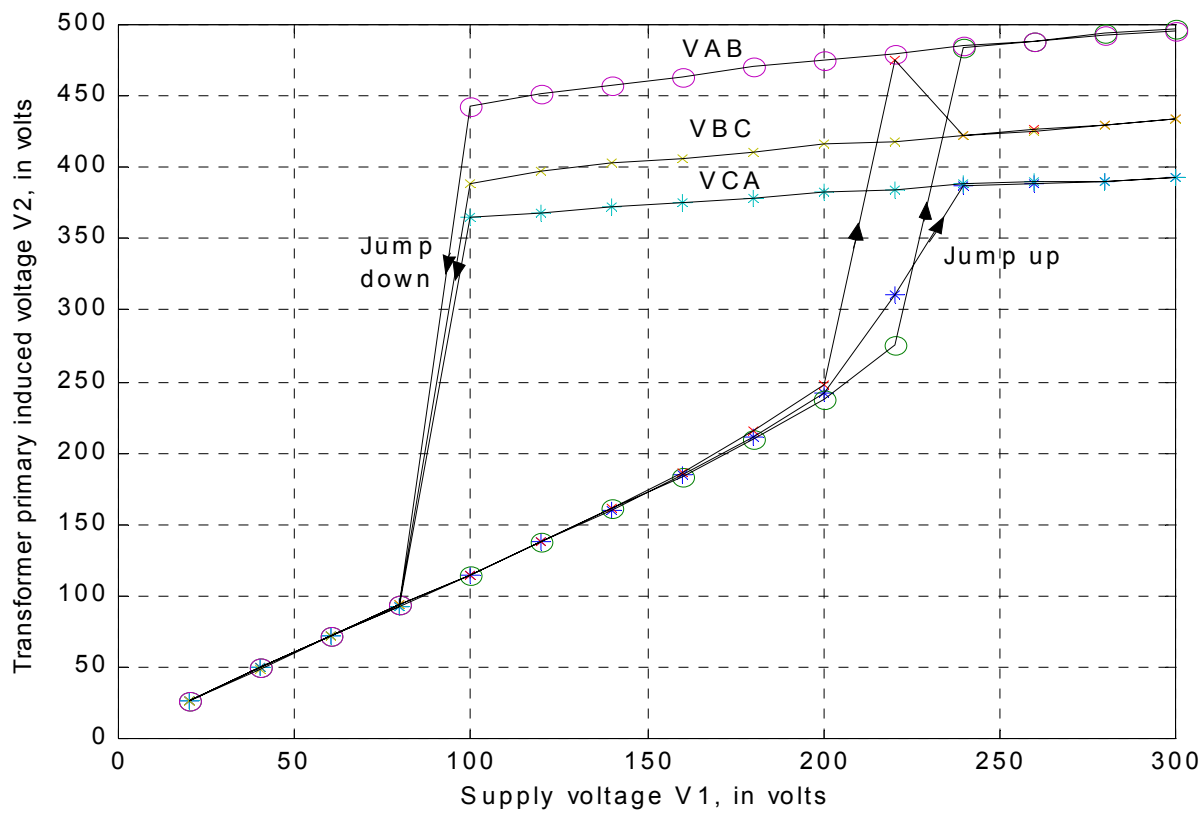

Fig. 2: Primary induced voltage, $V_{2}$, versus supply voltage, $V_{1}$ under no-load.

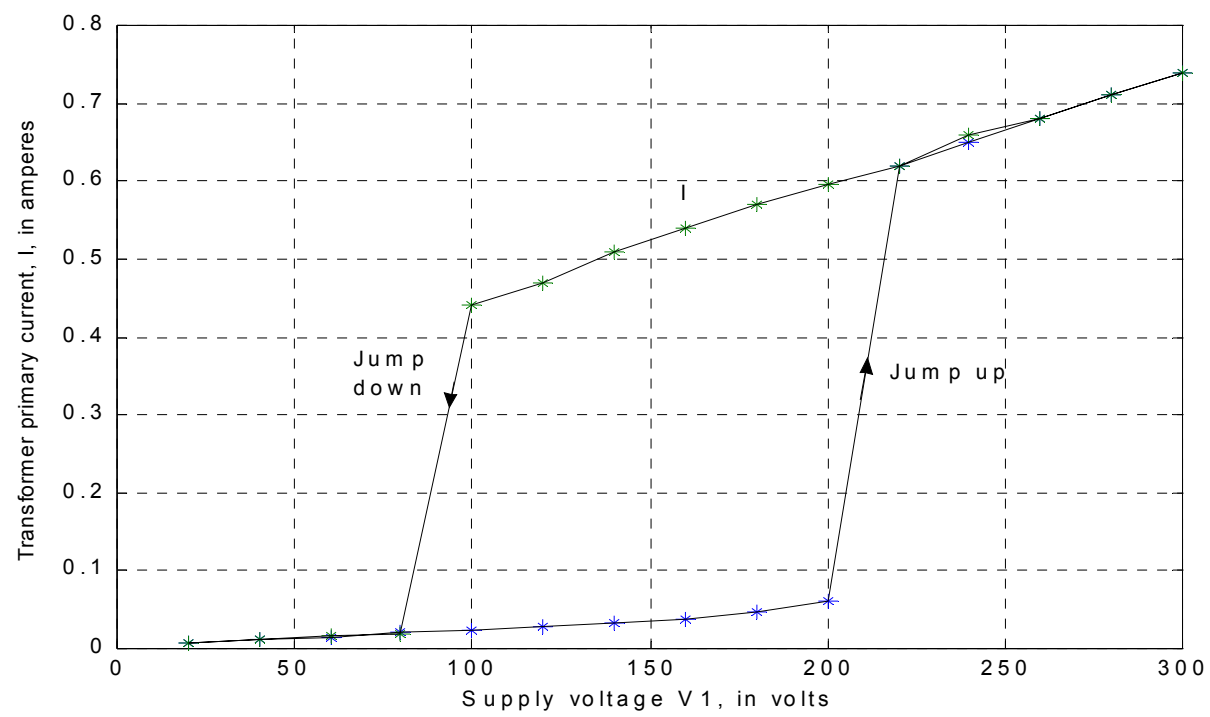

Fig. 3: Secondary induced voltage, $\mathrm{V}_{3}$, versus supply voltage, $\mathrm{V}_{1}$ under no- load. 


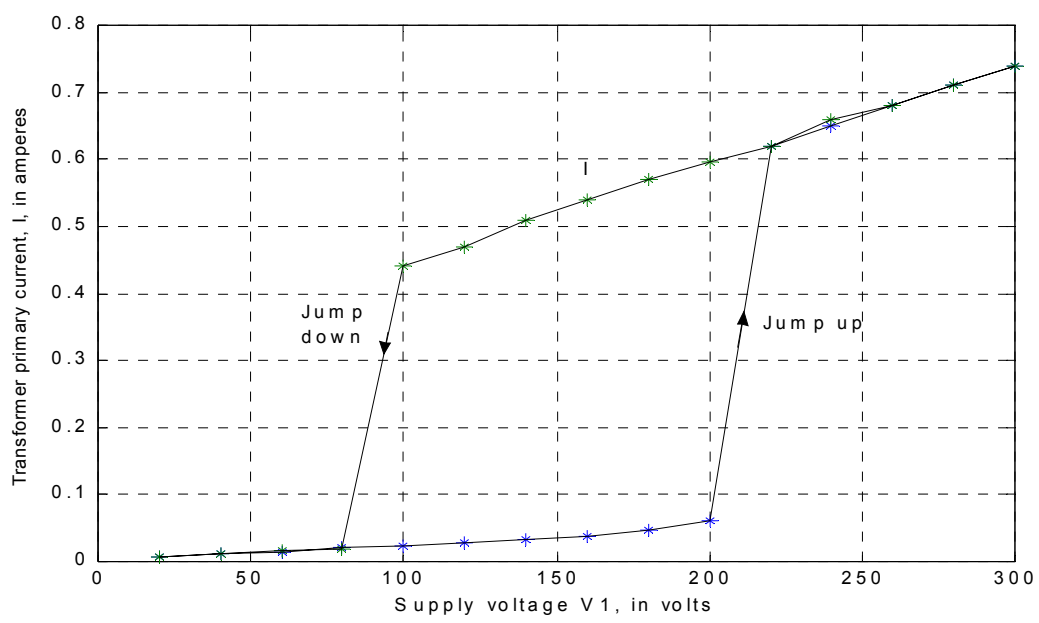

Fig. 4: Primary current, I, versus supply voltage, $\mathrm{V}_{1}$ under no-load.

\subsection{Unsymmetrical Switching of 3-Phase Transformer at No-Load}

In the circuit of Figure 1, a series capacitor of $\mathrm{C}=4.0 \mu \mathrm{F}$ has been used in series with only two primary phases (B and C) and connected to supply. Then, the supply voltage has been increased in steps from zero to $300 \mathrm{~V}$ and then reduced in steps also from $300 \mathrm{~V}$ to zero. In each step in the forward direction as well as in the backward direction, the readings of the supply voltage, $V_{1}$, the primary induced voltages, $V_{A B}, V_{B C}, V_{C A}$, the secondary induced voltages $V_{a b}$, $\mathrm{V}_{\mathrm{bc}}, \mathrm{V}_{\mathrm{ca}}$ and the primary current, I are recorded and depicted in figures 5-7.

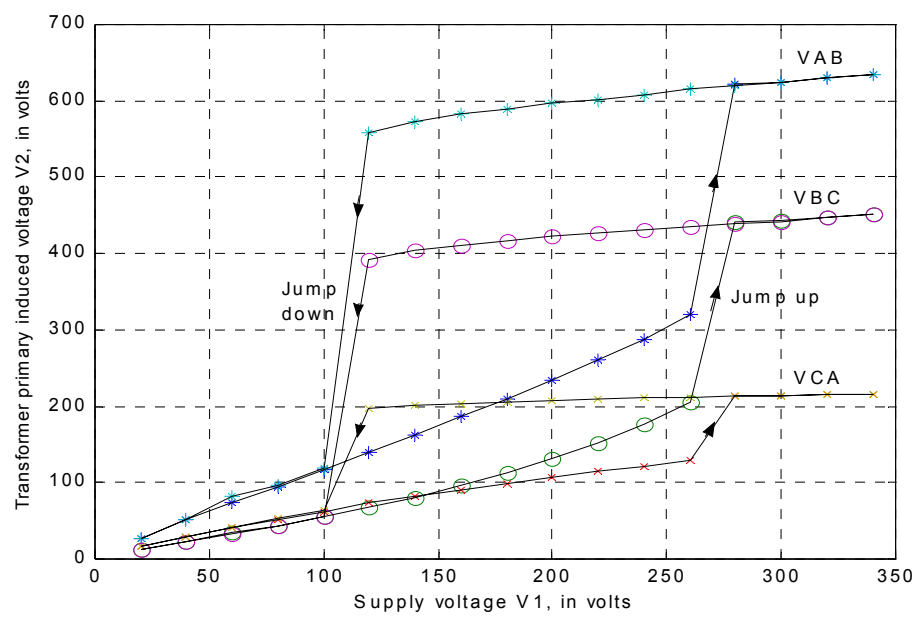

Fig. 5: Primary induced voltage, $V_{2}$, versus supply voltage, $V_{1}$ under no-load. 


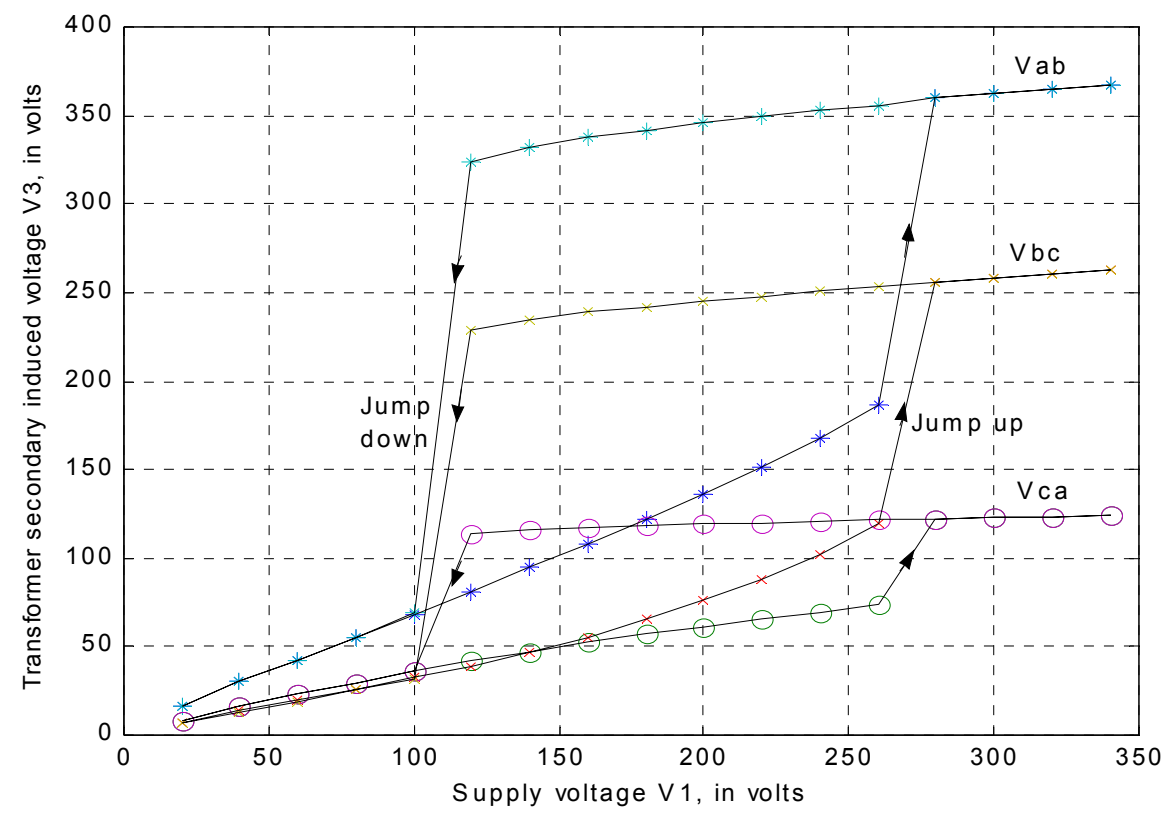

Fig. 6: Secondary induced voltage, $\mathrm{V}_{3}$, versus supply voltage, $\mathrm{V}_{1}$ under no-load.

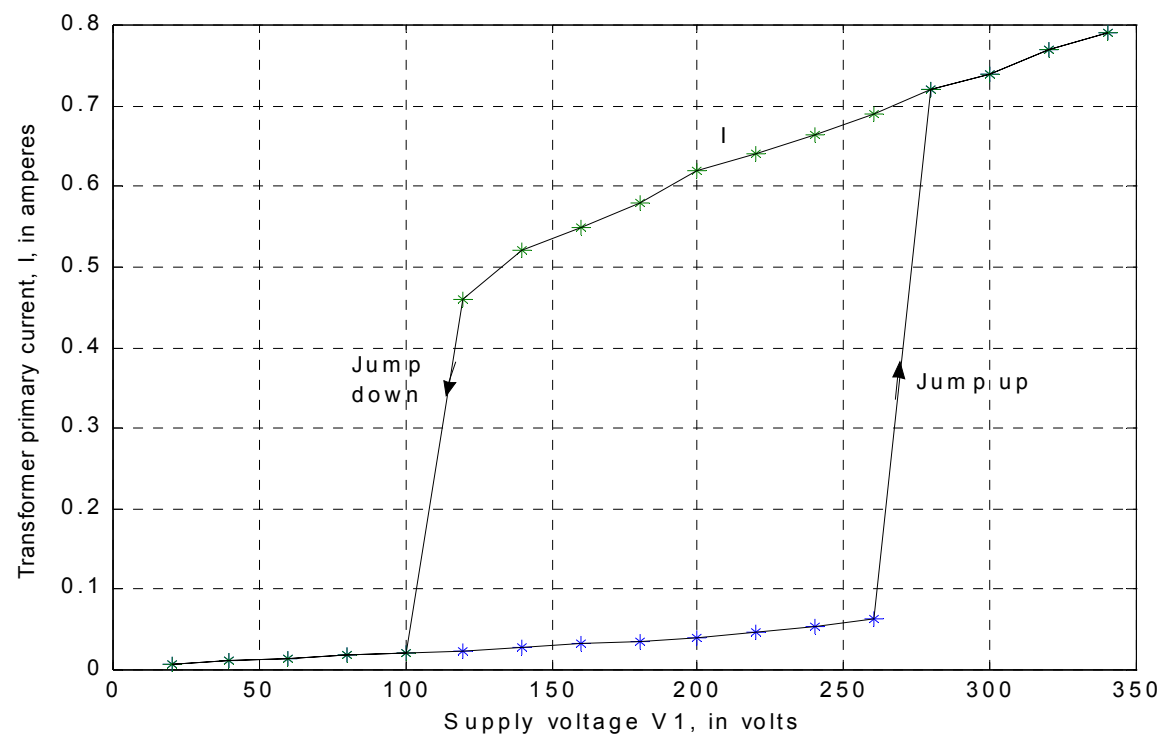

Fig. 7: Primary current, I, versus supply voltage, $\mathrm{V}_{1}$ under no-load. 
From Figures 5-7, it could be seen that a jump ferroresonance has occurred at supply voltage $\mathrm{V}_{1}=265$ volts causing:

1. Jump-up in the primary induced voltage that could reach as large as $\Delta \mathrm{V}_{\mathrm{AB}}$ $=300$ volts.

2. Jump-up in the secondary induced voltage that could reach as large as $\Delta \mathrm{V}_{\mathrm{ab}}=180$ volts.

3. Jump-up in the primary current that could reach as large as $\Delta \mathrm{I}=0.66$ amperes.

The jump-up ferroresonance caused by unsymmetrical switching is larger than that when all primary phases are connected to supply.

\subsection{Effect of Load on Ferroresonance}

The ferroresonance jump voltages have been measured under loading condition of the studied three-phase, core-type transformer. A three-phase constant load impedance $\mathrm{Z}_{\mathrm{L}}$ has been connected across the transformer secondary windings as shown in Figure 8. A series capacitor of $\mathrm{C}=4.0 \mu \mathrm{F}$ has been used with all primary phases are connected to supply. Then, the supply voltage has been increased in steps from zero to $300 \mathrm{~V}$ and then reduced in steps also from $300 \mathrm{~V}$ to zero. In each step in the forward direction as well as in the backward direction, the readings of the supply voltage, $V_{1}$, primary induced voltages, $\mathrm{V}_{\mathrm{AB}}, \mathrm{V}_{\mathrm{BC}}, \mathrm{V}_{\mathrm{CA}}$, secondary induced voltages $\mathrm{V}_{\mathrm{ab}}, \mathrm{V}_{\mathrm{bc}}, \mathrm{V}_{\mathrm{ca}}$ and the primary current, I are recorded and depicted in figures 9-11.

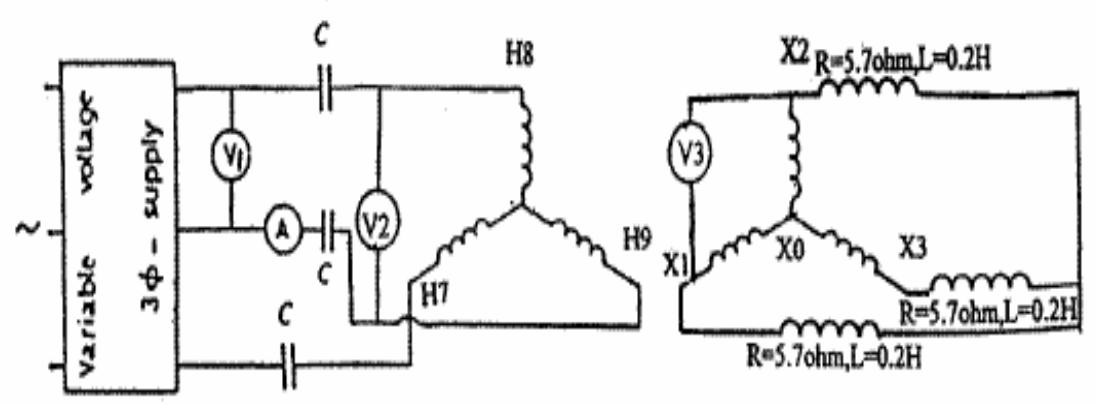

Fig. 8: Ferroresonance circuit diagram with transformer under load. 


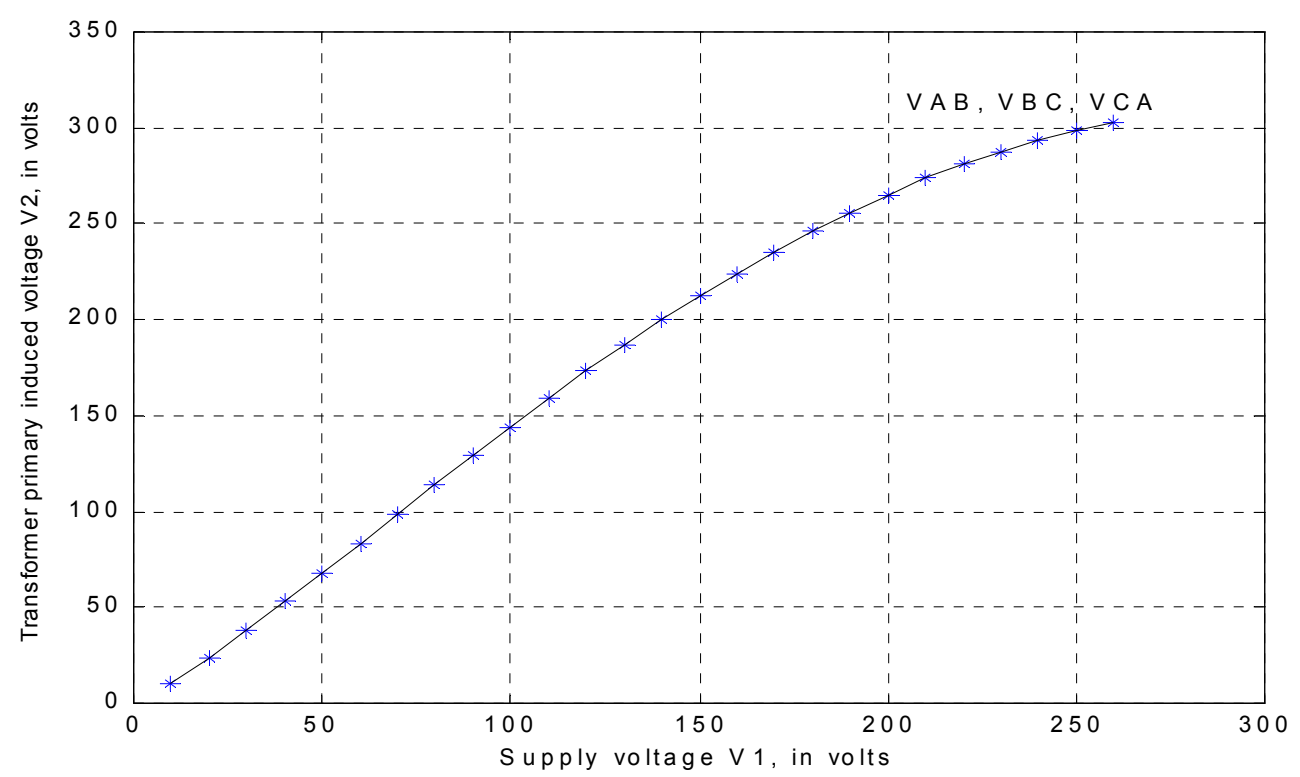

Fig. 9: Primary induced voltage, $V_{2}$, versus supply voltage, $V_{1}$ under load.

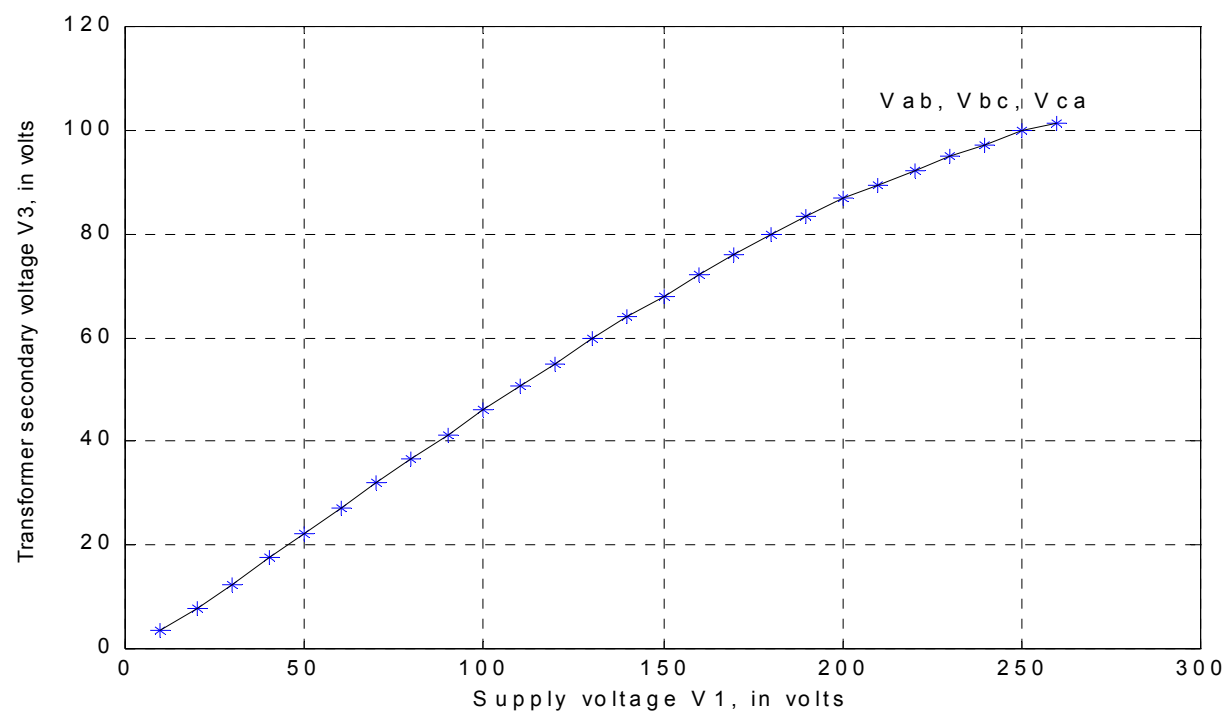

Fig. 10: Secondary induced voltage, $\mathrm{V}_{3}$, versus supply voltage, $\mathrm{V}_{1}$ under load. 


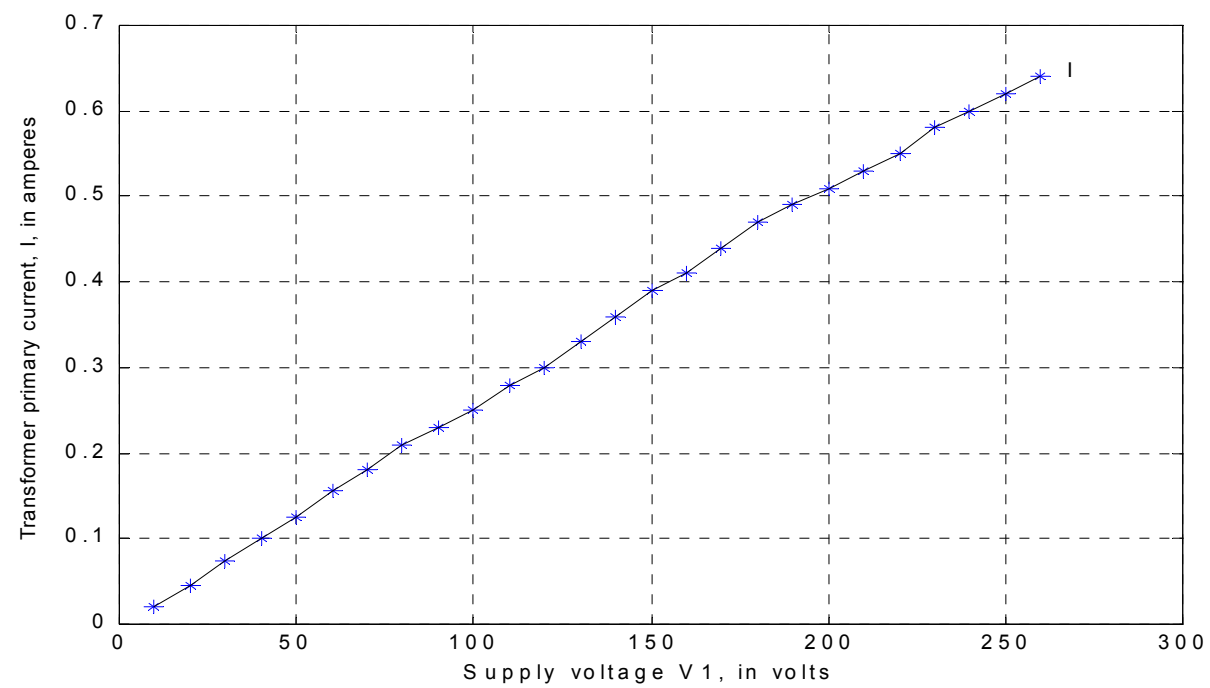

Fig. 11: Primary current, I, versus supply voltage, $V_{1}$ under load.

From figures 9-11, it could be seen that under the value of the load impedance $Z_{L}$ shown in Figure 8, no jump- voltage or jump- current are seen in the primary or secondary sides. This means that loading transformers will reduce and may prevent the jump resonance phenomenon.

\section{Conclusions}

From the experimental results of ferroresonance which are obtained in this investigation, it could be concluded that:

1. Ferroresonance can cause dangerous overvoltages and overcurrents in three-phase core-type transformers.

2. The largest values of the overvoltages and overcurrents caused by ferroresonance occur when the transformer is at no load.

3. The overvoltages and overcurrents caused by ferroresonance due to unsymmetrical switching are found to be larger than those obtained when all transformer phases are connected to supply.

4. The effect of transformer loading on the ferroresonance phenomenon in electrical power systems is to reduce or prevent it.

5. From this study, the following methods are to be suggested for reducing the ferroresonance overvoltages:

i. Reduce the system capacitances, preferring overhead transmission lines to under ground cables. 
ii. Reduce the transformer nonlinear reactance by designing the transformer to operate in the linear part.

iii. Avoid operating the transformer at no load condition by disconnecting the transformer primary terminals from supply in this case.

\section{References}

[1] Saied M.M., Abdallah H.M. and Abdallah A.S., Damping Effect of Load on the Ferroresonance Phenomenon in Power Networks, Electric Power System Research, 7, 271-277 (1984).

[2] Semlyen A., Acha A., Arril1aga J., Harmonic Norton Equivalent for the Magnetising Branch of a Transformer, IEE Proceedings-C, 134, 169-172 (1987).

[3] Jacobson D.A.N., Marti, L., Menzies, R.W., Modeling Ferroresonance in a 230 $\mathrm{kV}$ Transformer - Terminated Double - Circuit Transmission Line, Proc. of the 1999 International Conference on Power Systems Transients, Budapest, 451-456 (1999).

[4] Jacobson D.A.N., Menzies R. W., Investigation of Station Service Transformer Ferroresonance in Manitoba Hydro's 230-kV Dorsey Converter Station, Proc. IPST'2001, Intemational Conference on Power Systems Transients, Rio de Janeiro (2001).

[5] IEEE Working Group on Modeling and Analysis of Systems Transients, M.R. Iravani, Chair, Modeling and analysis guide- lines for slow transients- part III: the study of ferroresonance, IEEE Transactions on Power Delivery, 15, 255265 (2000).

[6] Tanggawelu B., Mukerjee R.N. and Ariffin A.E., Ferroresonance Studies in Malaysian Utility's Distribution Network, Proc. IEEE Power Engineering Society General Meeting, 2, 1216-1219 (2003).

[7] Beckley, P., Modern Steels for Transformers and Machines, Power Engineering Journal, 13, 4, 190-200 (1999). 


\section{ظاهرة الرنين الحسيدي في محولات القوى الكهربيائية - ققييمك معملية}

\section{لكمسسيد عبدا لـ ومحمد عبد الفلم الغاضي}

قنم الهنهة الكهربائية، كلية الهنهسة، جلمعة الملكسعود الرياض، المملكة العربية للسعويةية

المستخلص: في هذا البهث مُ إجراء درلسة معملية لظاهرة الرنين

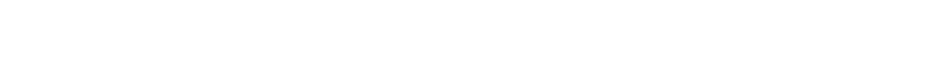
أوضحت هذه الدرلسة ما يلي:

1- ظاهرة الرنين الحيدي تسبب زيادات مفلجئة وخطيرة في الجهود والتيارات بكل من ملفات المحول الابتدائية والثانوية.

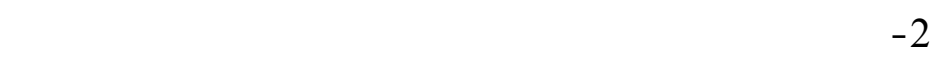
المحولات الكهربائية في حالة اللحالحل. 3- وجد أن قيم التيارات والجهود الزائية الناتجة عن ظاهرة الريات الرنين

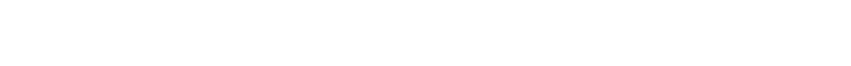
الكهربي (أحد لُٔارف المحول مفتوحة وغير مموصلة بالمصدر)

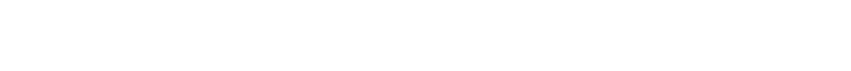
بالمصدر الكهربي. 4 - تأثير وجود حمل على المحول الكهربي وجد أنه يضغف وقد يمنع حدوثظاهرة الرنين الحديدي. 